\title{
Ot
}

\section{AIAA 99-2670}

Experimental Investigation of Convoluted Contouring for Aircraft Afterbody Drag Reduction

K. A. Deere and C. A. Hunter

NASA Langley Research Center

Hampton, VA
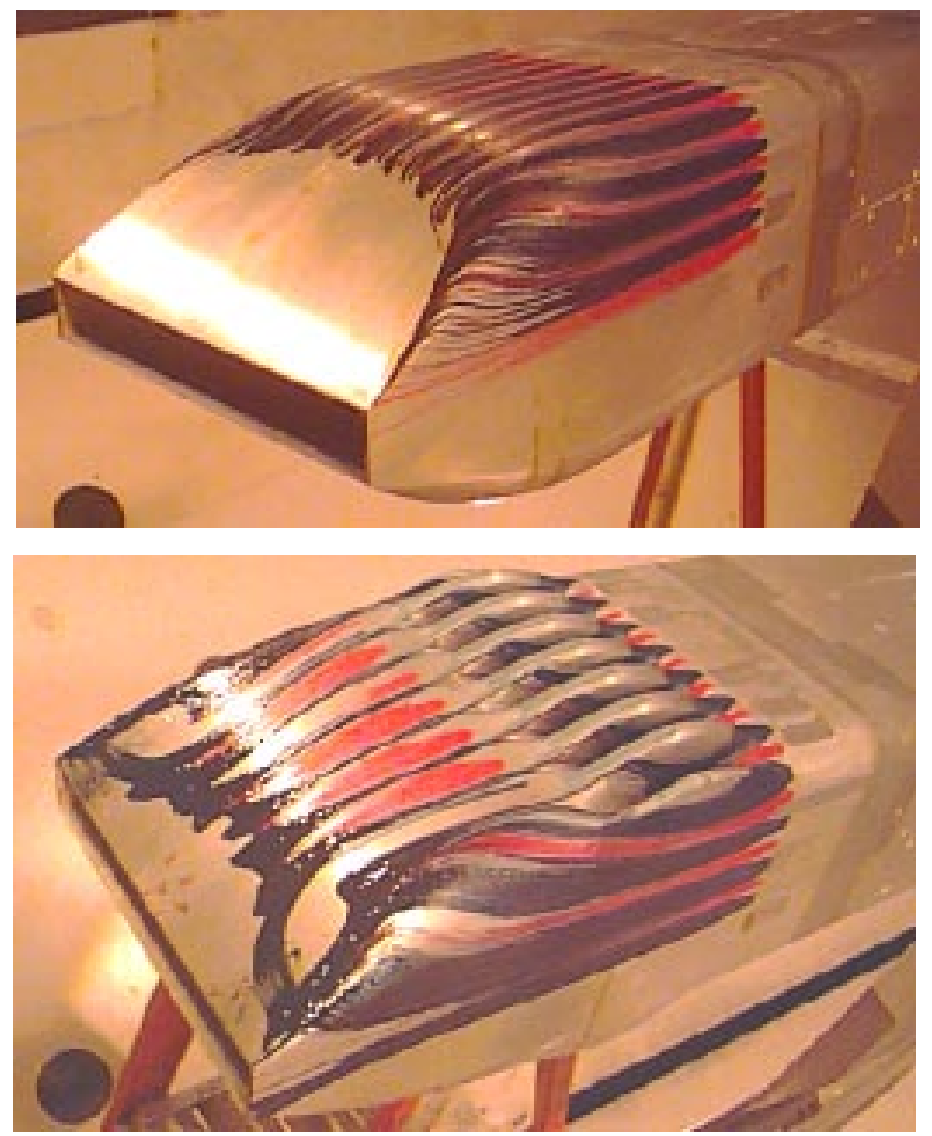

35th AIAA/ASME/SAE/ASEE Joint Propulsion Conference \& Exhibit June 20-24, 1999 / Los Angeles, CA 


\title{
Experimental Investigation of Convoluted Contouring for Aircraft Afterbody Drag Reduction
}

\author{
Karen A. Deere $\dagger$ and Craig A. Hunter $\dagger$ \\ NASA Langley Research Center \\ Hampton, VA
}

\begin{abstract}
$\underline{\text { ABSTRACT }}$
An experimental investigation was performed in the NASA Langley 16-Foot Transonic Tunnel to determine the aerodynamic effects of external convolutions, placed on the boattail of a nonaxisymmetric nozzle for drag reduction. Boattail angles of $15^{\circ}$ and $22^{\circ}$ were tested with convolutions placed at a forward location upstream of the boattail curvature, at a mid location along the curvature and at a full location that spanned the entire boattail flap. Each of the baseline nozzle afterbodies (no convolutions) had a parabolic, converging contour with a parabolically decreasing corner radius. Data were obtained at several Mach numbers from static conditions to 1.2 for a range of nozzle pressure ratios and angles of attack. An oil paint flow visualization technique was used to qualitatively assess the effect of the convolutions. Results indicate that afterbody drag reduction by convoluted contouring is convolution location, Mach number, boattail angle, and NPR dependent. The forward convolution location was the most effective contouring geometry for drag reduction on the $22^{\circ}$ afterbody, but was only effective for $M<0.95$. At $M=0.8$, drag was reduced 20 and 36 percent at NPRs of 5.4 and 7, respectively, but drag was increased 10 percent for $M=0.95$ at NPR $=7$. Convoluted contouring along the $15^{\circ}$ boattail angle afterbody was not effective at reducing drag because the flow was minimally separated from the baseline afterbody, unlike the massive separation along the $22^{\circ}$ boattail angle baseline afterbody.
\end{abstract}

\section{INTRODUCTION}

For an afterbody of a typical fighter aircraft that accounts for about 35 percent of the total aircraft length, it is often surprising that the afterbody is responsible for up to 50 percent of the total aircraft drag at transonic conditions. Approximately half of the afterbody drag results from adverse interference effects when integrating the propulsion system with the airframe, and from pressure drag on the afterbody (refs. 1-2). While propulsion airframe integration is of equal importance, this study focuses on the reduction of afterbody pressure drag.

Fighter aircraft encounter a wide range of flight conditions to perform a required mission. To maintain high performance, the nozzle geometry must be continuously optimized for changes in Mach number and

$\dagger$ Aerospace Engineer, Configuration Aerodynamics Branch, Aerodynamics Competency. Member AIAA

Copyright (C) 1999 by the American Institute of Aeronautics and Astronautics, Inc. No copyright is asserted in the United States under

Title 17, U.S. Code. The U.S. Government has a royalty-free license to exercise all rights under the copyright claimed herein for government purposes. All other rights are reserved by the copyright owner engine pressure ratio. However, mechanical variable area nozzles, intended to improve internal nozzle performance, also alter the external aft-end shape, closure, and boattail angle, often at the expense of external aerodynamic performance. In addition, attempts to shorten the length of the propulsion system to improve efficiency, decrease weight, and reduce skin friction drag can result in a short, steep boattail geometry at a dry power setting. The trade off is a geometry that can encourage flow separation and result in excessive drag. In such cases, external flow separation can occur at subsonic conditions when the boundary layer cannot overcome the adverse pressure gradient on the boattail. At transonic speeds, flow acceleration along the boattail terminates with a shock, and the resulting shock-boundary layer interaction leads to separation.

Previous work (ref. 3) has shown that convoluted contouring can alleviate, and in some cases eliminate, shock-induced boundary layer separation at transonic conditions. Convoluted contouring has also shown promise for alleviating separation in subsonic applications (refs. 4-5). Studies have indicated that convolutions can reduce bluff body drag by nearly 75 percent. In the current investigation, convoluted contouring was placed on a nozzle afterbody, shown in 
figure 1 , to evaluate the potential for reducing drag by alleviating separation.

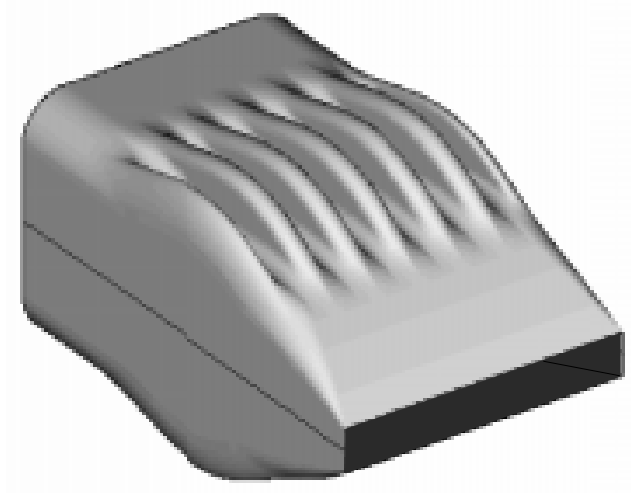

Figure 1. Convoluted contouring on an aircraft afterbody.

\section{NOMENCLATURE}

$A_{e} \quad$ exit area, $6.944 \mathrm{in}^{2}$

$A_{\text {ref }} \quad$ reference area, $42.396 \mathrm{in}^{2}$

$A_{t} \quad$ throat area, 4.972 in $^{2}$

$A_{e} / A_{t} \quad$ expansion ratio, 1.397

$C_{D} \quad$ total drag

$C_{D, f} \quad$ skin friction drag

$C_{D, p} \quad$ pressure drag, $C_{D}-C_{D, f}$

$C_{p} \quad$ pressure coefficient, $p-p_{\infty} / q_{\infty}$

$L \quad$ nozzle length, inches

$M \quad$ free stream Mach number

MS model station, inches

NPR nozzle pressure ratio, $p_{t, j} / p_{\infty}$

$p \quad$ surface static pressure, $\mathrm{psi}$

$p_{t, j} \quad$ average jet total pressure, $\mathrm{psi}$

$p_{\infty} \quad$ free-stream static pressure, $\mathrm{psi}$

$q_{\infty} \quad$ free-stream dynamic pressure, $\mathrm{psi}$

$x / L \quad$ normalized axial location along afterbody

$\alpha \quad$ angle of attack, deg

\section{APPARATUS AND EXPERIMENTAL METHODS}

\section{Wind Tunnel}

This investigation was conducted in the 16-Foot Transonic Tunnel at NASA Langley Research Center. This single-return, continuous-flow, atmospheric wind tunnel has a slotted octagonal test section and continuous air exchange. Variable airspeeds allow testing from Mach numbers of 0.3 to 1.2 . Test section plenum suction is used for Mach numbers above 1.05. The Reynold's number per foot varies from $3 \times 10^{6}$ at $M=0.6$ to $4 \times 10^{6}$ at
$M=1.2$. A detailed description of the facility and operating procedures are found in reference 6 .

\section{Model Installation and Support System}

The nozzle afterbody was attached to the singleengine propulsion simulation system and mounted in the tunnel on a sting strut, as shown in figure 2 . The model was composed of a forebody that covered the highpressure plenum, a centerbody that covered the lowpressure plenum and instrumentation section, and the nozzle afterbody. Hardware downstream of MS 26.9 was metric, or on a six-component force balance. The nozzle afterbody started at MS 54.486, and is defined as $x / L=0$ in the figures of pressure coefficient.

A standard grit application method was used on the model forebody to transition the boundary layer to turbulent flow. Number 100 silicon carbide grit particles were sparsely applied to a 0.1 -inch wide strip located 1.5 inches aft of the model nose tip.

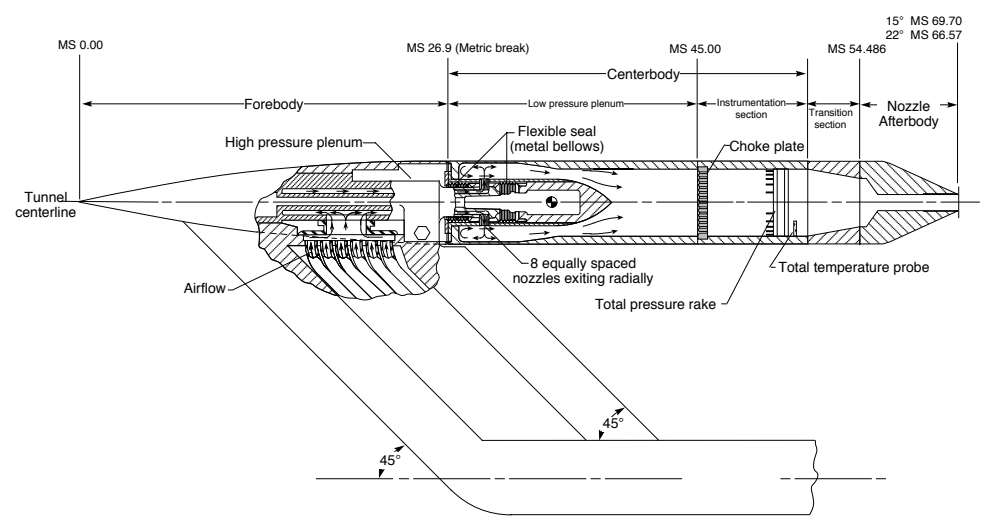

Figure 2. Single-engine propulsion simulation system with the nozzle afterbody on a sting-strut mount.

\section{Propulsion Simulation System}

An external high-pressure air system provided a continuous flow of clean, dry air at a stagnation temperature of approximately $540^{\circ} \mathrm{R}$ to the nozzle. Highpressure air was routed through six air lines in the support system to the nonmetric high pressure plenum. To minimize the axial momentum generated by transferring the air from the nonmetric, high-pressure plenum to the metric, low-pressure plenum, the air was discharged radially through eight equally spaced sonic nozzles. Flexible metal bellows were used to seal the air system between the plenums and minimize pressurization forces. Data were corrected for pressure force tares during the data reduction process. The air flowed from the lowpressure plenum, through a choke plate, into the 
AIAA 99-2670

instrumentation section, and exhausted through the test nozzle.

\section{Model Description}

This research effort was conducted to investigate the effect of convoluted contouring on the external afterbody of an exhaust nozzle, for alleviating separation and reducing total drag. The addition of convolutions to the external surface of the baseline afterbody shape increased surface area, and hence, skin friction drag. Wetted area estimates for each afterbody are shown in Table 1, and equivalent "flat plate" skin friction estimates are given in Table 2. Nozzles with boattail angles of $15^{\circ}$ and $22^{\circ}$ were tested with convolutions placed at a 'forward' location upstream of the boattail curvature, at a 'mid' location along the curvature, and at a 'long' location that spanned the entire boattail flap. The convolution locations are illustrated in figure 3 . Each baseline nozzle (no convolutions) had a parabolic, converging contour with a parabolically decreasing corner radius.

Convoluted contours were designed based on previous work (refs 3-5), and were characterized by vertical walls with constant radius hills and valleys. In the spanwise direction, each convolution cycle had an amplitude to period ratio of $0.6: 1$, or equivalently, a hill/valley height to width ratio of $2.4: 1$ (fig. 4(a)). In the streamwise direction, the convolution run was defined by a flattened bell curve and had a 7 to 10 percent height to length aspect ratio (fig. 4(b)). Contours were generated on an imaginary flat plate and then computationally faired onto the baseline afterbody shape.

All nozzle afterbodies had a convergent-divergent internal geometry with an expansion ratio of $A_{e} / A_{t}=1.397$ and a design nozzle pressure ratio (NPR) of 5.4. Drawings of the internal moldlines are shown in figure 5. The convergent section occurred for $x \leq 3$ inches in the xy plane (fig. 5(a)) and was defined with curve 2 (eqn. 1 ).

$y=0.093037 x^{3}-0.418667 x^{2}+1.756$

The internal geometry was designed with the divergent section in the xz plane to accommodate the depth of the convolution valley in the xy plane. The divergent section was dependent on the nozzle length $L$ and was defined with curve 3 for $x \geq 3$ inches (fig. 5(b)). Equations 2 and 3 define curve 3 for the $15^{\circ}$ and $22^{\circ}$ boattail angle nozzle afterbodies, respectively.

$z=-0.0011509 x^{3}+0.0313863 x^{2}-0.157244 x+2.70633$ $z=-0.0027705 x^{3}+0.0627048 x^{2}-0.301426 x+2.9007$

\begin{tabular}{|l|r|r|}
\hline & $15^{\circ}$ Nozzles & \multicolumn{1}{|c|}{$22^{\circ}$ Nozzles } \\
\hline Baseline & 354.17 & 288.64 \\
\hline Forward & 429.01 & 351.25 \\
\hline Mid & 494.38 & 390.21 \\
\hline Long & 526.88 & 421.82 \\
\hline \hline
\end{tabular}

Table 1: Nozzle wetted area, square inches.

\begin{tabular}{|l|c|c|c|c|}
\hline & $\mathrm{M}=0.6$ & $\mathrm{M}=0.8$ & $\mathrm{M}=0.9$ & $\mathrm{M}=1.2$ \\
\hline $15^{\circ}$ Baseline & 0.019 & 0.018 & 0.018 & 0.017 \\
\hline $15^{\circ}$ Forward & 0.024 & 0.023 & 0.022 & 0.021 \\
\hline $15^{\circ}$ Mid & 0.028 & 0.027 & 0.027 & 0.025 \\
\hline $15^{\circ}$ Long & 0.031 & 0.029 & 0.029 & 0.027 \\
\hline $22^{\circ}$ Baseline & 0.015 & 0.014 & 0.014 & 0.013 \\
\hline $22^{\circ}$ Forward & 0.019 & 0.018 & 0.018 & 0.017 \\
\hline $22^{\circ}$ Mid & 0.021 & 0.020 & 0.020 & 0.019 \\
\hline $22^{\circ}$ Long & 0.024 & 0.023 & 0.022 & 0.021 \\
\hline \hline
\end{tabular}

Table 2: Nozzle skin friction drag coefficient, $C_{D, f}$

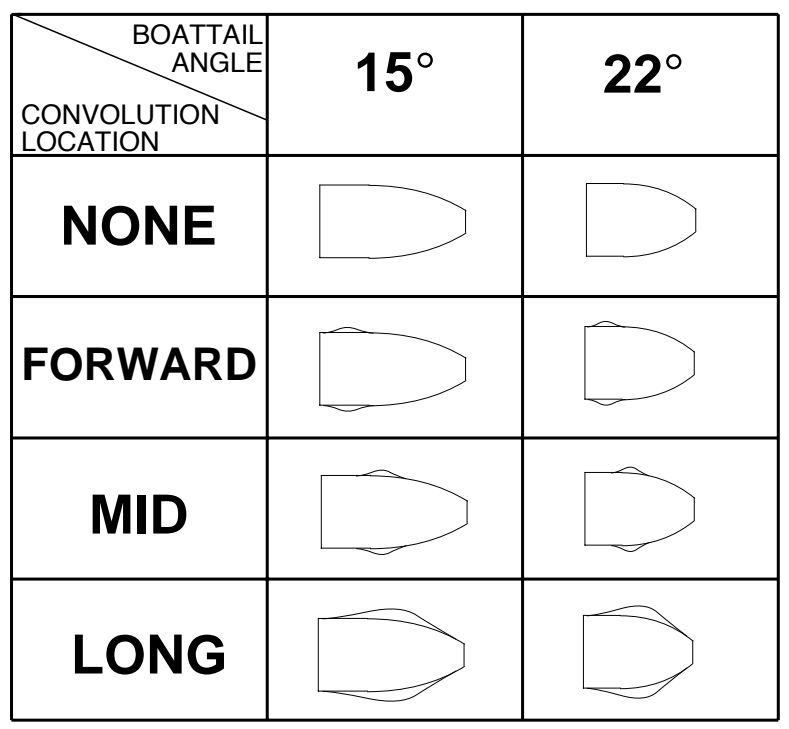

Figure 3. Matrix of boattail angle and convolution location. 


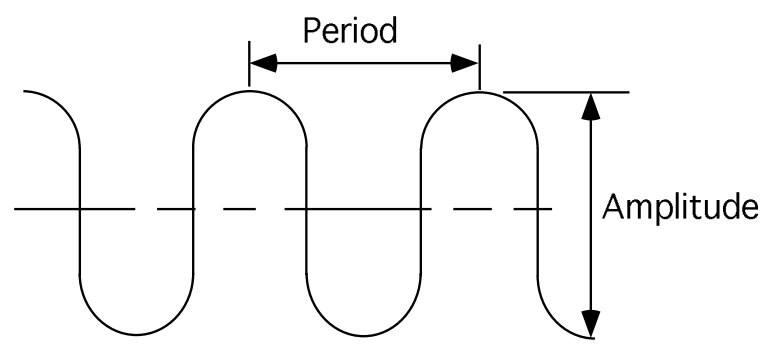

(a) Spanwise profile

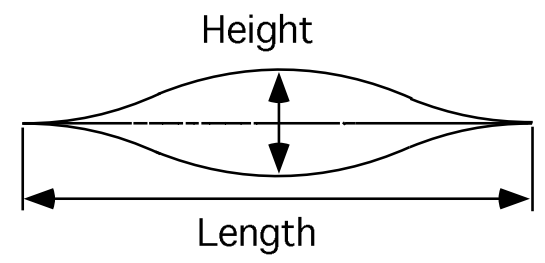

(b) Streamwise profile

Figure 4. Spanwise and streamwise convolution profiles.

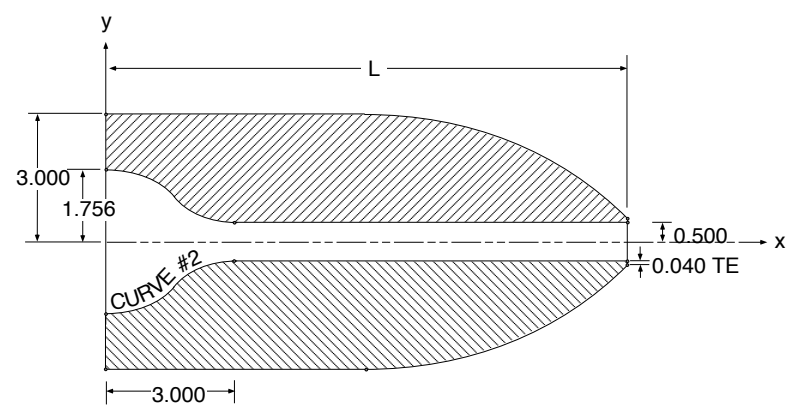

(a) Side View

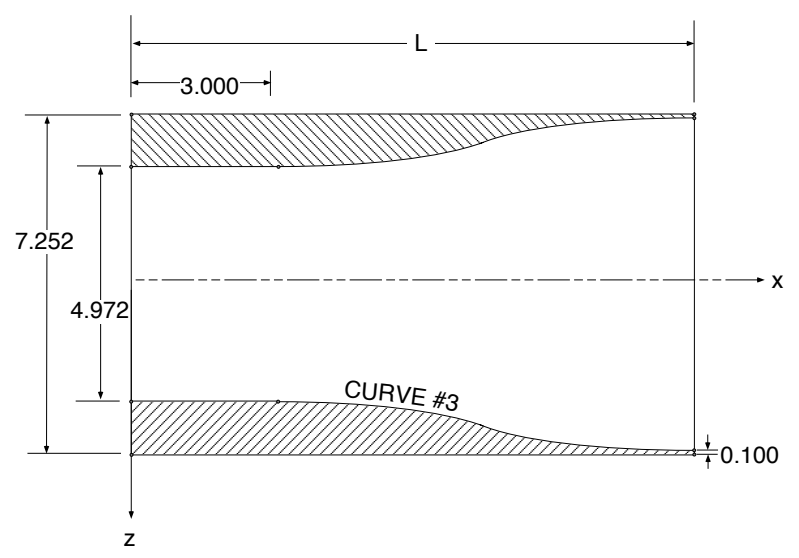

(b) Top View

Figure 5. Nozzle internal moldlines.

\section{Instrumentation}

An internal six-component strain-gauge balance was used to measure external and internal forces and moments acting on the model downstream of MS 26.9 (fig. 2). Weight flow was measured with a multiple-critical venturi located in the high-pressure air system. Jet total pressure and total temperature were measured with a tenprobe total pressure rake and an iron-constantan thermocouple located in the instrumentation section. Jet total pressure and venturi static pressures were measured with individually sized transducers. Nozzle internal and external static pressures were measured with electronically-scanning pressure (ESP) modules located in the model forebody.

The convoluted afterbodies had three longitudinal, rows of external pressure orifices, one located near the sidewall, one near the centerline on the top of a convolution, and one near the centerline in the valley between two convolutions. The last pressure tap in each row, $x / L=1$, was located in the aft-facing, base end region. Baseline nozzles had two rows of longitudinal pressure orifices, one located near the sidewall and one at the centerline. All nozzles had seven internal pressure orifices.

Angle of attack was measured with an accelerometer in the strut head and corrected for sting deflections and tunnel flow angularity. The average flow angularity measured in the tunnel was $0.1^{\circ}$ of upflow.

\section{Data Acquisition and Reduction}

All data for the wind tunnel parameters and the model were recorded simultaneously. Steady-state data were obtained by averaging 50 frames of instantaneous data sampled at a rate of $10 \mathrm{~Hz}$. Final force and moment data were obtained by correcting each measured balance component for model weight tares, for balance component interactions, and for jet-off balance interactions. A detailed description of the data reduction procedure is given in reference 7 .

Data were taken with increasing nozzle pressure ratio (NPR), which is the ratio of jet total pressure $p_{t, j}$ to free-stream static pressure $p_{\infty}$. Balance-measured, thrustremoved, total drag coefficient $C_{D}$ was comprised of pressure drag coefficient $C_{D, p}$ and skin friction drag coefficient $C_{D_{f} f}$. Skin friction drag was computed by the method of Frankl and Voishel for compressible, turbulent flow on a flat plate (ref. 7). Balance-measured pressure drag was obtained by subtracting skin friction drag from 
balance-measured, total drag. Coefficients were calculated by normalizing drag force with free-stream dynamic pressure $q_{\infty}$ and a reference area of 42.396 inches. Pressure coefficient $\left(C_{p}\right)$ distributions are shown as a function of normalized axial location $x / L$, where pressure coefficient is defined as the difference between surface static pressure $p$ and free-stream static pressure, normalized by the free-stream dynamic pressure

\section{Flow Visualization}

Oil paint, thinned with linseed oil, was used to visualize flow patterns along the nozzle surfaces. It provided an excellent aid for interpreting pressure and force data. A row of paint dots, alternating in color, were applied normal to the flow direction at the nozzle connect station. Alternating the paint colors provided easier detection of streamline patterns. The tunnel set condition was held for approximately 2-3 minutes to allow the flow to move and dry the paint along the streamline path. Photographs were taken after the tunnel was shut down.

\section{Test Schedule}

Data were acquired at Mach numbers of $0.6,0.8$, $0.9,0.95$, and 1.2 , and model angles of attack $(\alpha)$ of $-5^{\circ}$, $0^{\circ}, 5^{\circ}$ and $10^{\circ}$. Data were taken at a constant Mach number and $\alpha$, while varying nozzle pressure ratio from 1 (jet-off) to 12 .

\section{$\underline{\text { RESULTS }}$}

Data are presented with effect of boattail angle along the baseline nozzle afterbodies first, followed by the effects of adding convolutions to the $22^{\circ}$ and the $15^{\circ}$ boattail angle afterbodies. All data presented were acquired at zero degree angle of attack.

\section{Baseline Comparisons}

The $15^{\circ}$ baseline nozzle afterbody had less total drag at both $M=0.8$ and 1.2 than the $22^{\circ}$ baseline nozzle afterbody, as shown in figures 6 and 7 , respectively. The $15^{\circ}$ baseline nozzle afterbody was 15.18 in. long and had more wetted surface area than the $22^{\circ}$ baseline nozzle afterbody, which was 12.09 in. long. Therefore, the $15^{\circ}$ baseline afterbody produced more skin friction drag than the $22^{\circ}$ baseline afterbody at all Mach numbers (see Table 2). After removing the contribution of skin friction drag from total drag, it is obvious that the shorter, steeper $22^{\circ}$ afterbody produced more pressure drag than the longer, shallow $15^{\circ}$ afterbody at all NPR for both subsonic (fig. 6(b)) and supersonic (fig. 7(b)) conditions.

Pressure coefficient distributions along the centerline of the $15^{\circ}$ and $22^{\circ}$ baseline afterbodies for various NPRs at $M=0.8$ are shown in figure 8 . The nozzle afterbody starts at MS 54.486, which is defined as $x / L=0$. The pressure tap located at $x / L=1$ was not an afterbody static pressure tap, but was located in the aftfacing, base end of the nozzle. The data indicates that the flow remained attached along the $15^{\circ}$ boattail afterbody at this Mach number. A strong shock, followed by shockinduced separation near $x / L=0.7$, occurred along the steep $22^{\circ}$ boattail afterbody. The $22^{\circ}$ baseline afterbody produced more drag because the steeper boattail resulted in more expansion near $x / L=0.5$ and pressures were lower on the aft-facing afterbody, compared to the $15^{\circ}$ baseline afterbody.

Pressure coefficient distributions along the centerline of the $15^{\circ}$ and $22^{\circ}$ baseline nozzle afterbodies for various NPR at $M=1.2$ are shown in figure 9 . Compared to the $M=0.8$ case, the pressure coefficient was lower for both boattail angles over the last 40 percent of the afterbody at supersonic conditions, which resulted in higher drag. Based on the pressure data in figure 9, it appears that the flow had enough momentum to remain attached to the shallow, $15^{\circ}$ afterbody until $x / L=0.88$, resulting in flow separation over the last 12 percent of the afterbody. The flow along the steeper, $22^{\circ}$ afterbody appeared to separate near $x / L=0.7$. Drag was higher on the $22^{\circ}$ afterbody than on the $15^{\circ}$ afterbody because the pressures were much lower over a larger region of the boattail (30 percent compared to 12 percent). In addition, the steep $22^{\circ}$ boattail had more aft-facing area for the pressures to act in the axial direction. Therefore, the convolutions had more of a chance to effect the adverse flow conditions along the $22^{\circ}$ baseline afterbody than the $15^{\circ}$ baseline afterbody.

The effects of nozzle pressure ratio on total drag are greater on the $15^{\circ}$ afterbody than on the $22^{\circ}$ afterbody at $M=1.2$ (fig. 7). The pressure data indicates larger differences in pressure recovery along the aft end of the $15^{\circ}$ afterbody, especially near $x / L=0.8$, compared with the $22^{\circ}$ afterbody separation. The shock located downstream of $x / L=0.7$ appeared to get stronger (higher pressures) as NPR increased, which resulted in a decrease in drag (fig. 7).

Streamline patterns along the $22^{\circ}$ baseline afterbody at $M=0.8$ and $M=0.95$ for a NPR $=7$ are shown in figures 10 and 11 , respectively. The paint covered only 70 percent of the boattail, indicating massive separation 
over 30 percent of the afterbody at both Mach numbers. Even though the streamline patterns look remarkably similar, total drag was 38 percent higher at $M=0.95$. The difference in nozzle drag can be explained with the pressure distributions along the afterbody. The pressure coefficient distributions along the $22^{\circ}$ baseline afterbody centerline and sidewall for $M=0.8$ and $M=0.95$ at an NPR $=7$ are shown in figure 12 . The shock was stronger at $\mathrm{M}=0.95$, as seen by the quick, steep increase in pressure near $x / L=0.7$. After the flow expanded at $x / L=$ 0.55 , the flow attempted to adjust to ambient conditions, but separated from the afterbody downstream of the shock near $x / L=0.8$ for $M=0.8$ and near $x / L=0.7$ for $M=$ 0.95 conditions. Drag was higher at $M=0.95$ because the pressures were lower than the $M=0.8$ case for $x / L>$ 0.7 . In addition, pressures acting on the last 50 percent of the afterbody have more impact on drag than $x / L<0.5$ because of the larger aft-facing area.

\section{$22^{\circ}$ Boattail Angle, Convoluted Afterbody}

The effect of convoluted contouring on the total drag of the $22^{\circ}$ boattail angle afterbody, at freestream Mach numbers of $M=0.8,0.9,0.95$, and 1.2, is shown in figures 13-16, respectively. Results indicate that the effectiveness of convoluted contouring on the afterbody boattail is dependent on freestream Mach number, NPR, and convolution location. None of the convolution locations reduced drag relative to the baseline at $M=1.2$. The forward convolutions were the most effective at reducing drag for $M<0.95$. At $M=0.8$, the forward convolutions reduced total drag nearly 20 percent at the design nozzle pressure ratio, $\mathrm{NPR}_{\mathrm{D}}=5.4$. In general, the long convolutions increased skin friction and pressure drag relative to the baseline afterbody for $M>0.8$.

Convoluted contouring in the forward location energized the boundary layer and the flow remained attached further downstream on the afterbody. The delay of separated flow was "visualized" with oil paint, and the results are shown in figures 17 and 18 , for an NPR $=7$, at $M=0.8$ and 0.95 , respectively. The streamlines on the baseline afterbody (figs. 10 and 11) indicated more separation than on the forward convoluted afterbody at both Mach numbers (figs. 17 and 18). However, compared to the baseline afterbody, the forward convolutions reduced drag 36 percent at $M=0.8$, but increased drag 10 percent at $M=0.95$. The pressure coefficient distributions in figures 19 and 20 for $M=0.8$ and $M=0.95$, help to illustrate the Mach number dependence of the forward convolutions. The forward convolutions energized the flow to allow pressure recovery to positive values of pressure coefficient over the aft 20 percent of the boattail at $M=0.8$ (fig. 19(a)), which resulted in thrust on the aft-facing boattail. The convoluted contouring delayed separation at $M=0.95$, but the expansion near $x / L=0.6$ was greater and the shock was stronger relative to the baseline (fig. 20), resulting in increased drag. The flow did not recover to positive values of pressure coefficient along the $22^{\circ}$ forward convoluted afterbody as it did under $M=0.8$ conditions. The last pressure tap was in the trailing edge surface, and was pressurized by the internal flow at underexpanded conditions.

Convoluted contouring was not effective at decreasing total drag at supersonic conditions because of wave drag (fig. 16). At supersonic conditions the convolutions created shock waves that reduced total pressure, increased entropy, and inevitably, increased drag. As shown in figures 14 and 16 at NPR $=5.4$, the forward convolutions decreased drag 5 percent at $M=0.9$, but increased drag nearly 20 percent at $M=1.2$. The pressure coefficient distributions along the $22^{\circ}$ baseline and forward convoluted nozzle afterbodies at $M=1.2$ and NPR $=7$ are shown in figure 21. The convolutions caused pressurization on the forward-facing surfaces between $x / L=0.2$ and 0.4 , increasing drag relative to the baseline. Similar to the $M=0.95$ case (fig. 20), the convolutions delayed separation, but caused the expansion of the flow along the centerline at $x / L=0.7$ to reach lower $C_{p}$, which resulted in more drag than the baseline afterbody produced. The flow on both the baseline and forward convoluted afterbody separated with negative values of pressure coefficient (drag on the aft-facing surface).

\section{$15^{\circ}$ Boattail Angle, Convoluted Afterbody}

The effect of convoluted contouring on the total drag of the $15^{\circ}$ boattail angle afterbody, at freestream Mach numbers of $M=0.6,0.9$, and 1.2 , is shown in figures 22-24, respectively. The convolutions were not effective on the $15^{\circ}$ afterbody. As expected, the convolutions increased skin friction drag (see Table 2), but also increased nozzle pressure drag at all Mach numbers. As with the $22^{\circ}$ convoluted nozzle afterbodies at $\mathrm{M}=1.2$, the $15^{\circ}$ convoluted nozzle afterbodies had greater total drag than the baseline due to wave drag. After removing the contribution of skin friction drag from the measured total drag, it is obvious, as shown in figure 25 , that pressure drag was higher for the convoluted cases than for the baseline afterbody. As discussed previously, the $15^{\circ}$ baseline afterbody had much less, and in some cases, no separated flow to influence relative to the $22^{\circ}$ baseline afterbody. 


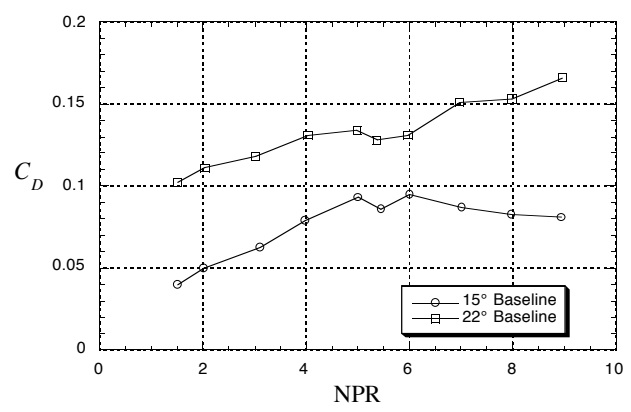

(a) Total drag coefficient

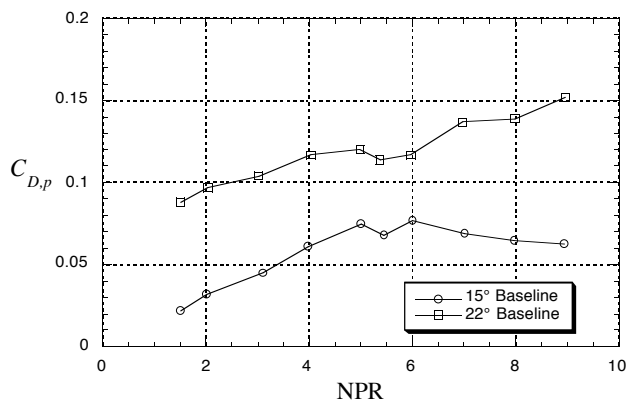

(b) Pressure drag coefficient

Figure 6. Baseline nozzle afterbodies, $M=0.8$.

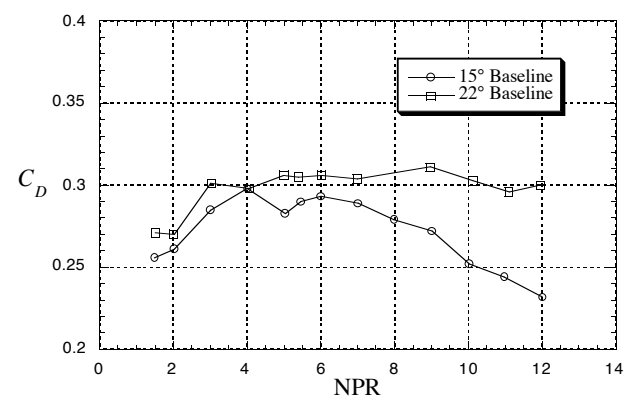

(a) Total drag coefficient

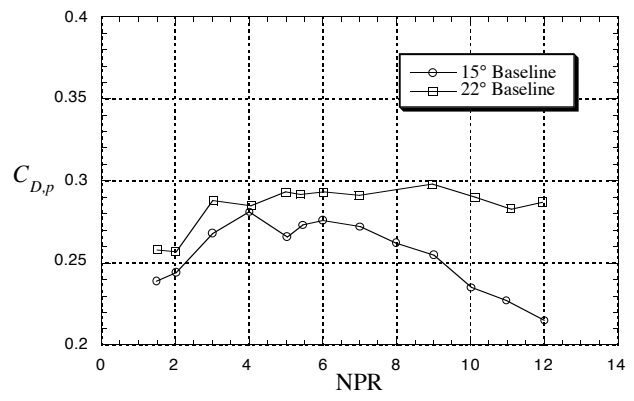

(b) Pressure drag coefficient

Figure 7. Baseline nozzle afterbodies, $M=1.2$.

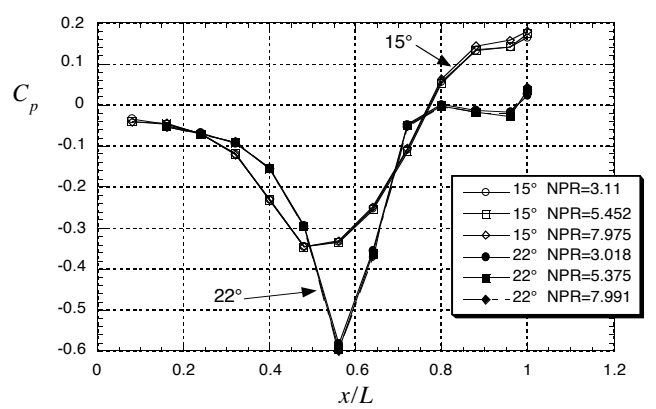

Figure 8 . Centerline pressure coefficient distributions, $15^{\circ}$ and $22^{\circ}$ baseline afterbodies at selected NPR, $M=0.8$.

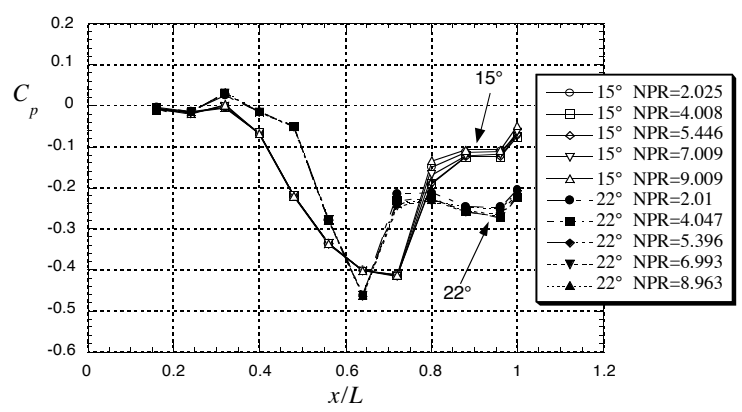

Figure 9. Pressure coefficient distributions along the centerline, $15^{\circ}$ and $22^{\circ}$ baseline afterbodies, $M=1.2$.

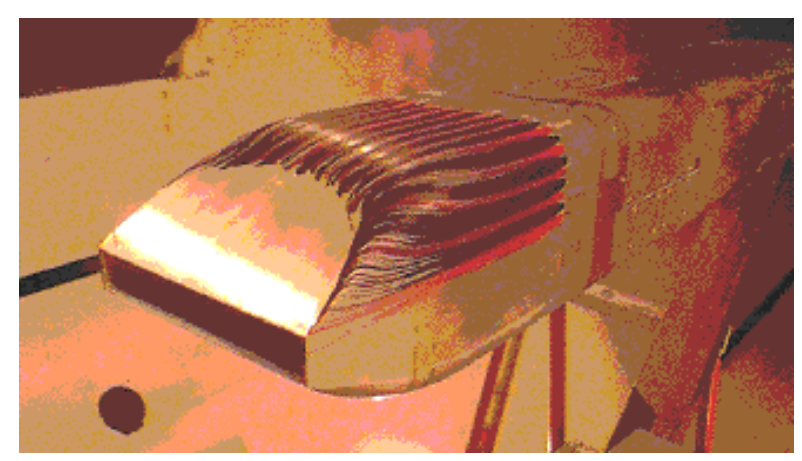

Figure $10.22^{\circ}$ Baseline afterbody at $M=0.8, \mathrm{NPR}=7$.

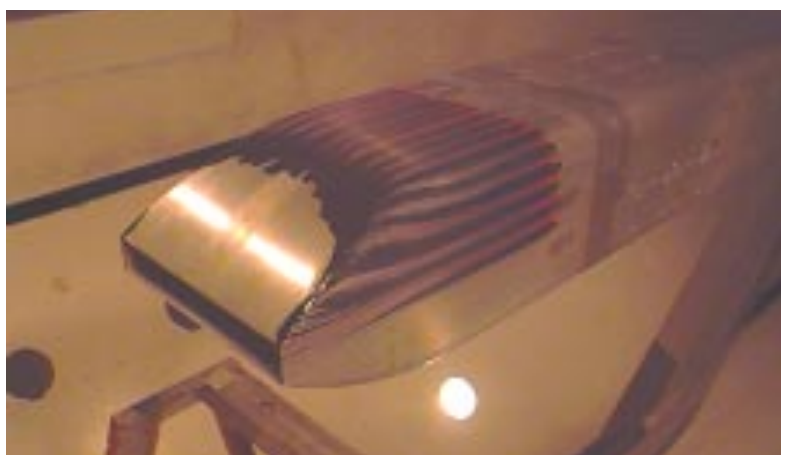

Figure 11. $22^{\circ}$ Baseline afterbody at $M=0.95, \mathrm{NPR}=7$. 


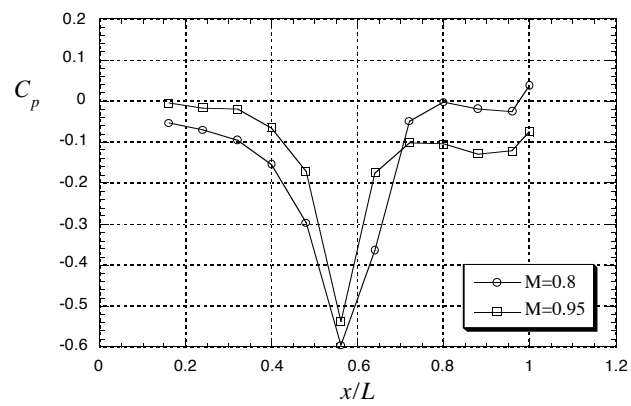

(a) Centerline

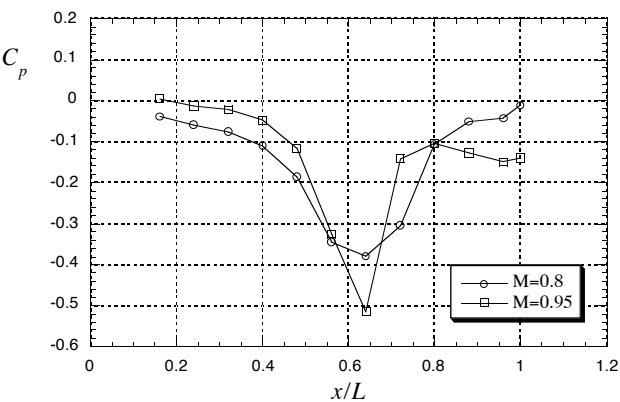

(b) Sidewall

Figure $12.22^{\circ}$ Baseline comparison, $M=0.8$ and $M=$ $0.95, \mathrm{NPR}=7$.

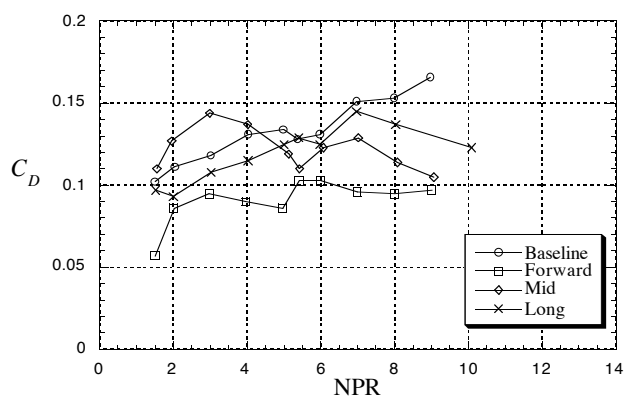

Figure 13. Effect of convolutions on total drag, $22^{\circ}$ boattail angle, $M=0.8$.

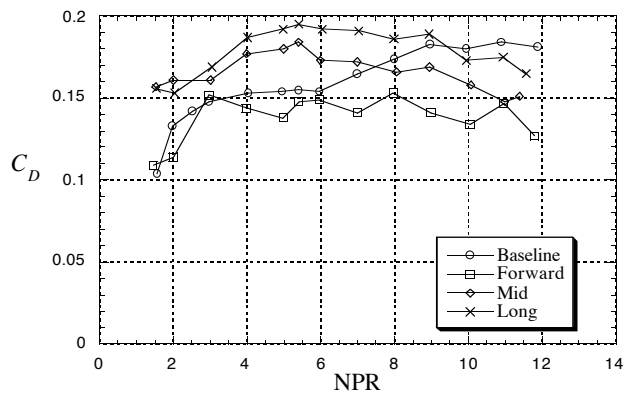

Figure 14. Effect of convolutions on total drag, $22^{\circ}$ boattail angle, $M=0.9$.

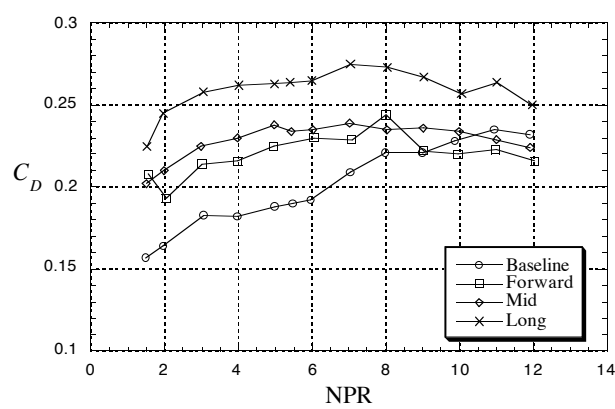

Figure 15. Effect of convolutions on total drag, $22^{\circ}$ boattail angle, $M=0.95$.

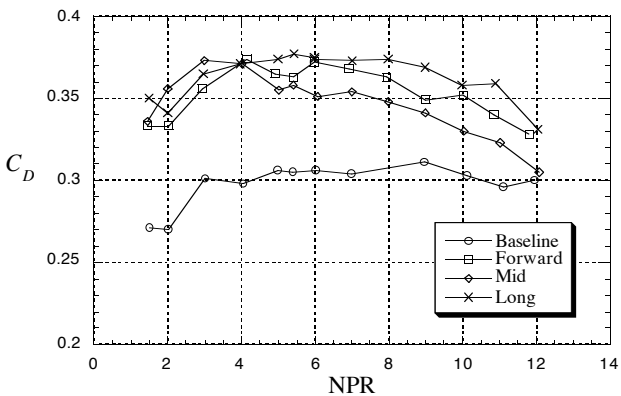

Figure 16. Effect of convolutions on total drag, $22^{\circ}$ boattail angle, $M=1.2$.

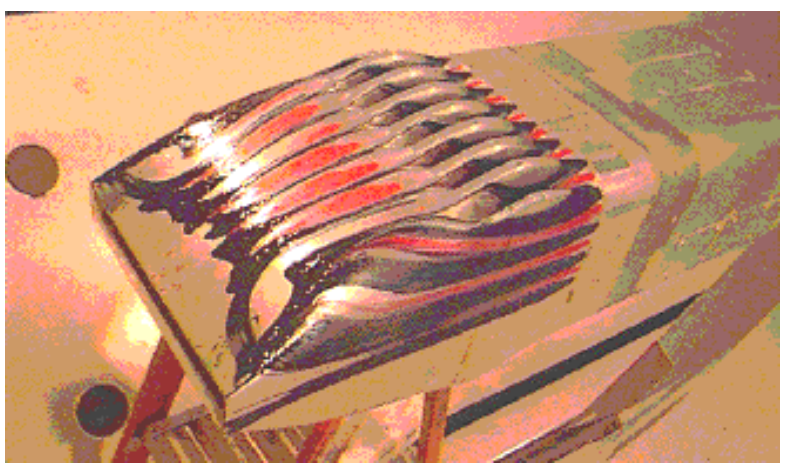

Figure 17. Forward convolutions delay separation on the $22^{\circ}$ afterbody at $M=0.8, \mathrm{NPR}=7$.

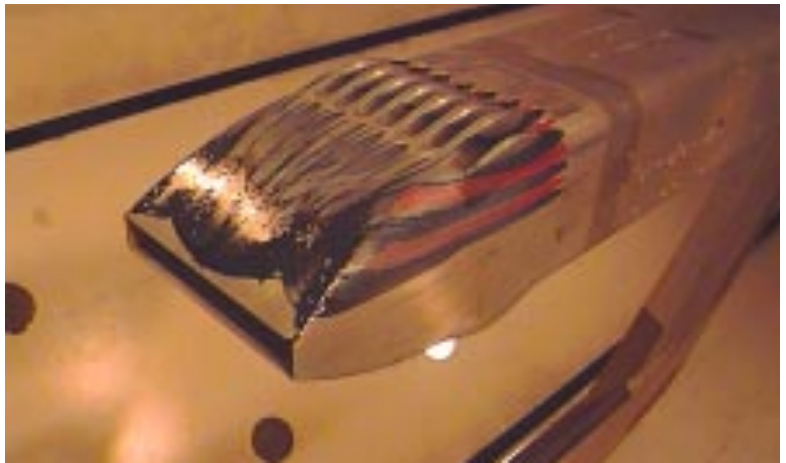

Figure 18. Forward convolutions delay separation on the $22^{\circ}$ afterbody at $M=0.95, \mathrm{NPR}=7$. 


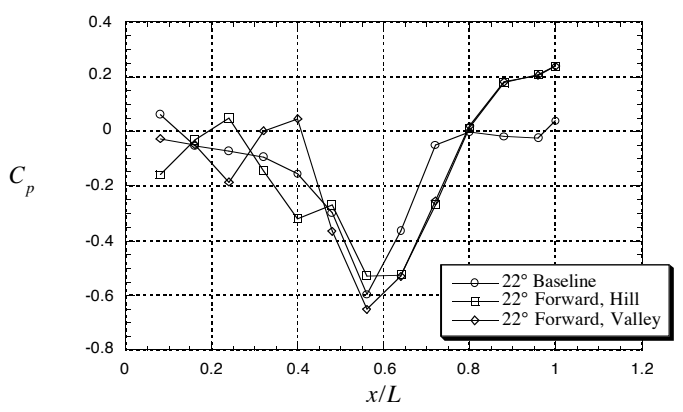

(a) Centerline

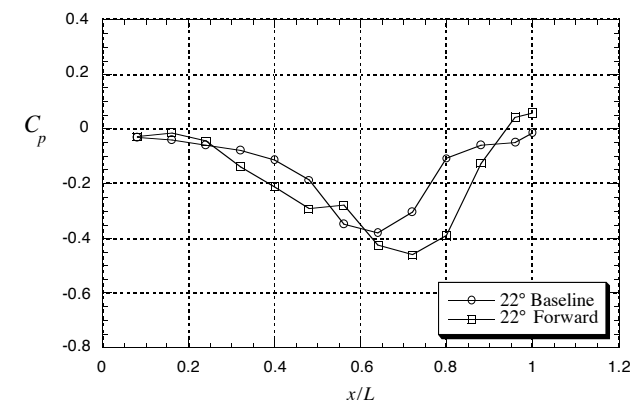

(b) Sidewall

Figure 19. Forward convolutions delay separation on the $22^{\circ}$ afterbody at $M=0.8, \mathrm{NPR}=7$.

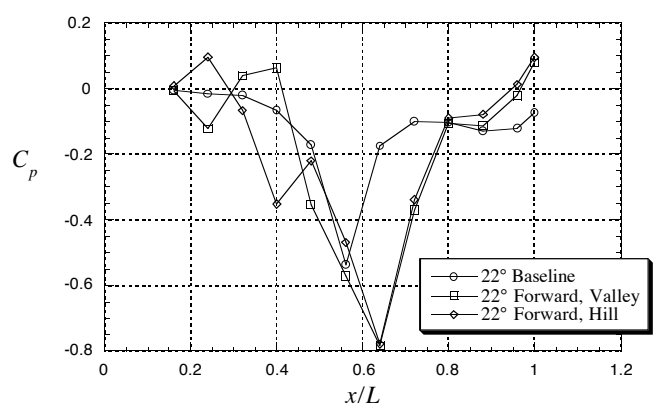

(a) Centerline

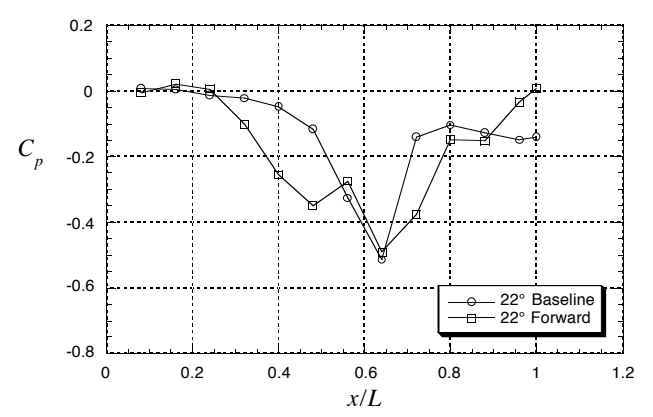

(b) Sidewall

Figure 20. Forward convolutions delay separation on the $22^{\circ}$ afterbody at $M=0.95, \mathrm{NPR}=7$.

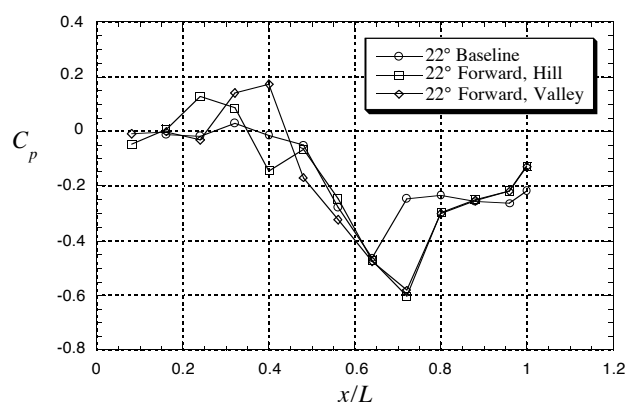

(a) Centerline

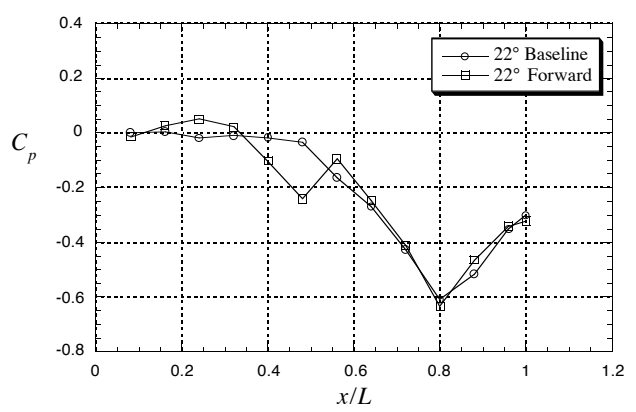

(b) Sidewall

Figure 21. Pressure coefficient distributions along the $22^{\circ}$ baseline and forward convolution afterbodies, $M=1.2, \mathrm{NPR}=7$.

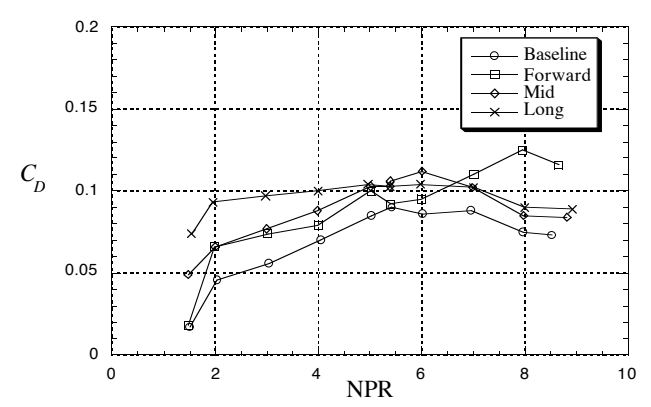

Figure 22. Effect of convolutions on total drag, $15^{\circ}$ boattail angle, $M=0.6$.

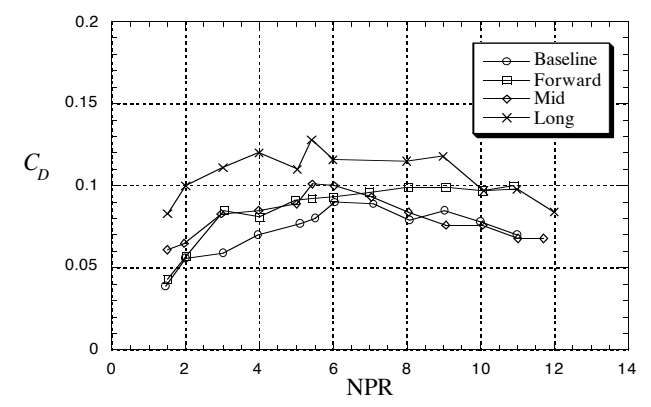

Figure 23. Effect of convolutions on total drag, $15^{\circ}$ boattail angle, $M=0.9$. 


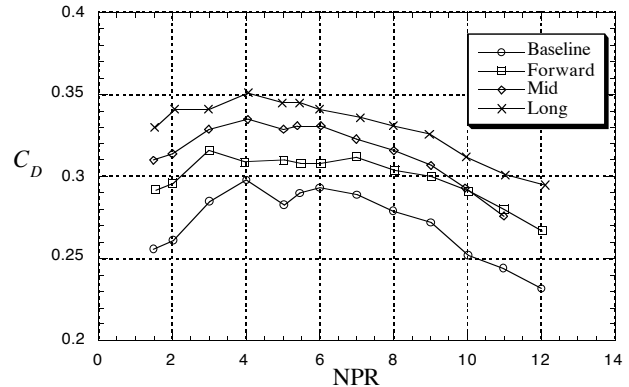

Figure 24. Effect of convolutions on total drag, $15^{\circ}$ boattail angle, $M=1.2$.

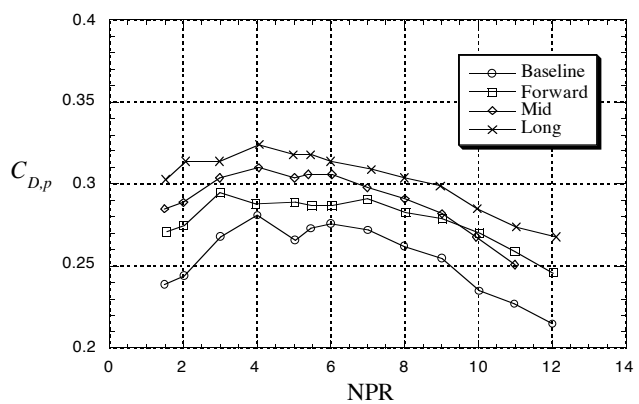

Figure 25. Effect of convolutions on nozzle pressure drag, $15^{\circ}$ boattail angle, $M=1.2$.

\section{CONCLUSIONS}

Adding convolutions to the baseline nozzle afterbodies increased wetted area and therefore, increased skin friction drag, one component of total drag. The effectiveness of the convolutions at decreasing pressure drag, the other component of total drag, was convolution location, Mach number, boattail angle, and NPR dependent.

The $22^{\circ}$ baseline afterbody had more separation along the boattail (due to the short, steep boattail geometry) than the longer, more gradual $15^{\circ}$ baseline afterbody. At $M=1.2$, the flow was separated over the last 30 percent of the $22^{\circ}$ baseline afterbody, and over the last 12 percent of the $15^{\circ}$ baseline afterbody. Therefore, the convolutions had an opportunity to influence a larger region of separated flow on the $22^{\circ}$ boattail angle afterbody. In fact, none of the convolution locations were effective at decreasing drag on the $15^{\circ}$ boattail angle afterbody at any Mach number.

The forward convolution location was the most effective contouring geometry for drag reduction on the $22^{\circ}$ afterbody, but the convolutions were only able to reduce drag for $M<0.95$. At $M=0.8$, drag was reduced 20 and 36 percent at NPRs of 5.4 and 7, respectively. Drag was increased 10 percent for $M=0.95$ at NPR $=7$. In either case, the convolutions delayed separation, but only when the pressure on the boattail recovered to higher values than the baseline, was the drag reduced. At $M=0.8$, pressure recovered to positive values of pressure coefficient on the aft-facing boattail, which resulted in a thrust component over part of the afterbody, or drag reduction.

None of the convolution locations were effective at decreasing drag on the $22^{\circ}$ afterbody for $M>0.95$, due to supersonic wave drag. Shocks formed on the forwardfacing contours at $M=1.2$, increasing pressure drag relative to the baseline. In addition, the contouring delayed separation, but the flow expanded to even lower pressures than on the baseline, increasing drag further.

\section{$\underline{\text { REFERENCES }}$}

1. Corson, B. W., Jr., and Runckel, J. F.: Exploratory Studies of Aircraft Afterbody and Exhaust-Nozzle Interaction. NASA TMX-1925, 1969.

2. Runckel, J. F.: Interference Between Exhaust System and Afterbody of Twin-Engine Fuselage Configurations. NASA TN D-7525, 1974.

3. Hunter, C. A.: An Experimental Analysis of Passive Shock-Boundary Layer Interaction Control for Improving the Off-Design Performance of Jet Exhaust Nozzles. Master of Science Thesis, George Washington University/NASA Langley Research Center, September 1993.

4. Presz, W. M., Jr.; Werle, M.; and Paterson, R. W.: Trailing Edge Separation/Stall Alleviation. Journal of Propulsion and Power, Volume25, 1987.

5. Presz, W. M., Jr. et al.: Rippled Afterbody Performance Study. United Technologies Research Center Report UTRC87-27, September 1987.

6. Capone, Francis J.; Bangert, Linda S.; Asbury, Scott C.; Mills, Charles T.; and Bare, E. Ann: The NASA Langley 16-Foot Transonic Tunnel Historical Overview, Facility Description, Calibration, Flow Characteristics, Test Capabilities. NASA TP-3521, 1995.

7. Mercer, C. E., Berrier, B. L., Capone, F. J., and Grayston, A. M.: Data Reduction Formulas for the 16-Foot Transonic Tunnel at NASA Langley Research Center, Revision 2. NASA TM-107646, 1992. 